
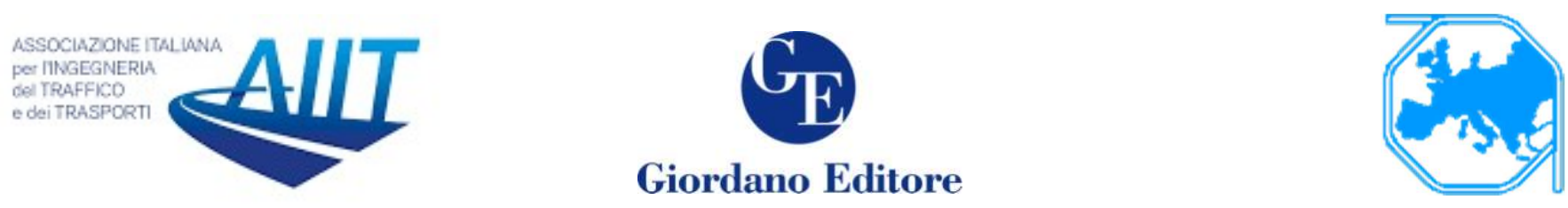

\title{
Stated interest, actual use or indifference towards car sharing: profiling students and staff of a university campus in Turin (Italy)
}

\author{
Miriam Pirra $^{1 *}$, Marco Diana ${ }^{1}$

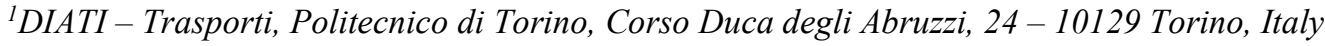

\begin{abstract}
A mobility survey was proposed to the staff and to the students of Politecnico di Torino (a technical university located in Turin, Italy) in autumn 2016 with a focus on the interest and on the current use of car sharing. Turin is in fact offering a relatively broad variety of such services, with several different operators and a fleet of about 700 vehicles. A data mining technique, named co-clustering, is then applied to the dataset of 1314 answers in order to characterise respondents' profiles and assess to which extent specific combinations of variables describing personal, travel-related or satisfaction with travel aspects are associated with the actual use, the interest or the lack of interest in car sharing. Early adopters of car sharing are more frequently encountered among students than among staff and show more multimodal behaviours. The levels of use of different modes can be helpful in discriminating between mere positive attitudes towards car sharing and actual intention to use it, while travel related satisfaction ratings are rather indicating the interest or lack of interest in this service. Among university workers, younger females living in the outer part of the metropolitan city showed a good interest in car sharing, although the service is not available in the place where they live. Policy implications of such findings within a mobility management perspective are discussed.
\end{abstract}

Keywords: car sharing, clustering, data mining, mobility management, mobility to university.

\section{Introduction}

Car sharing is gaining, in recent years, a wide diffusion in many cities as a flexible and convenient mode of transport. The main factors of this success stand both on the consumer and on the community point of view and cover a wide range of benefits such as economic advantages for the drivers and the potential reduction of vehicle ownership and emissions (Shaheen and Cohen, 2013). Concerning the diffusion of car sharing in Italy, it can be said that the service appeared firstly in 2001 in Milan and then started spreading in around 30 big and medium sized cities, for an approximated number of 5,700 cars circulating in 2016 (Osservatorio nazionale sulla sharing mobility, 2016). Focusing on the city of Turin, which is the field of the experimental activities that are reported in this paper, the first

* Corresponding author: Miriam Pirra (miriam.pirra@polito.it) 
station-based car sharing provider appeared in November 2002. In February 2017, a fleet of 610 vehicles was declared to be available in this city (Urbi, 2017), while its number reached 750 cars at the end of the same year. Two different providers are offering a free floating service with a homogeneous fleet of conventionally fuelled compact cars, while a third one is a station-based one way service with plug-in electric vehicles. Some technical reports provide interesting statistics related to the diffusion of this new mode of transport at Italian level, together with some customers profiling and future trends. For example, a recent study presented by URBI, a mobile app aggregating shared mobility systems, analysed data of the main car sharing providers in Italy in the semester September 2016-February 2017 (Urbi, 2017). The city of Turin revealed the highest increase in the number of journeys $(+54 \%)$, against an average increase of $+35 \%$, despite the decrease of the fleet size $(-8 \%)$.

By contrast, fewer scientific studies on car sharing in Italy are available in the literature despite a rather wide diffusion of the service. Morgavi and Di Loreto (2017) focus on business models and implemented a survey in some of the Italian cities where car sharing is available. They show that this is mainly seen as a service complementing public transport rather than a direct substitute of the private car. In other words, when car sharing is available it tends to be jointly considered with public transport as an alternative to the use of a personal vehicle. Car sharing is chosen because of its higher flexibility, compared to public transport, and better parking availability, compared to the private car, even if $42 \%$ of the sample would not give up their personal vehicle to switch to car sharing. Given the high car ownership levels in Italy (620 cars each 1,000 inhabitants), the Authors conclude that car sharing could become an alternative to private cars through the creation of sharing intermodality centres. Bignami et al. (2017) study an electric car sharing service in Milan, analysing the whole process leading to its implementation. Some final guidelines can help in identifying the conditions that could to a shift from car ownership to vehicle sharing at city level. Other recent works proposed at Italian level focus, instead, on more technical issues on the provision of the service, as the estimation of number of vehicles of a fleet that are necessary to meet the expected requests of users (Marchionni, Ponti and Studer, 2017).

One common approach of the above referenced works is to consider car sharing as a component within the general transport system of a city or territory. Considering such aggregate viewpoint, their market share is still almost negligible compared to that of the most used modes such as feet, cars and public transport, despite the spectacular growth of shared mobility in recent years. As highlighted by Costain et al. (2012), it is therefore not easy to measure mobility impacts of car sharing in urban areas at an aggregate level. An alternative research perspective is therefore to focus on specific groups of users, for example to investigate the potential role of car sharing in the management of the mobility of a given community. Recent researches showed, in fact, that car sharing users are mainly young people, more educated, with fewer owned cars than the average, generally living in denser urban areas (Kopp, Gerike and Axhausen, 2015; Clewlow, 2016; Clewlow and Mishra, 2017; Dias et al., 2017). In particular, university campuses could be interesting case studies on these topics, since they collect a large number of young people usually interested in new technologies and sensitive to both cheaper and more sustainable modes of transport. Car sharing could therefore play a more incisive role in such contexts. Within this framework, this paper profiles students and staff of an Italian university to investigate their interest towards this service. 
Beyond car sharing, the body of research provides different examples of how the mobility in campus could be investigated and analysed (Lavery, Páez and Kanaroglou, 2013; Erdoğan, Cirillo and Tremblay, 2015; Zhou, 2016). Many studies aim at defining, through surveys and models, those policies and innovative actions that could be operated at university level in order to promote more sustainable ways of reaching the campuses (Shannon et al., 2006; Moniruzzaman and Farber, 2018). The main idea is to understand which are the barriers that prevent users from switching to greener and less polluting modes (Balsas, 2003; Schneider and $\mathrm{Hu}, 2014$ ). Campuses constitute mobility attractors that can significantly contribute to congestion and environmental impacts of transport systems. This is indeed the case of many Italian universities. For example, Longo et al. (2015) surveyed the daily mobility of students and staff of the University of Trieste, which represent a community of 25,000 people in a city of around 200,000 inhabitants. Opinions on those measures that could improve their journeys to the campus were collected and provided input for the implementation of transport measures. The same university of Trieste has been object of other studies investigating the effectiveness and the efficiency of some transport policies (Rotaris and Danielis, 2014, 2015). In this case, revealed and stated choice data are used to estimate a transport demand model which could help also other campus mobility managers to design better transport policies. The approach proposed in the current paper aims at studying mobility habits and attitudes towards car sharing services of another Italian campus located in Turin. However, this is done through a "leaner" methodology based on a data mining technique, which is used to identify groups of travellers in order to propose some policy recommendations according to their characteristics. Compared to more commonplace modelling approaches that are discussed in many of the above mentioned papers, this method can better investigate the intertwined relationships between disparate factors (socioeconomic characteristics, mobility patterns, attitudinal factors) that jointly interact to shape car sharing-related choices, albeit on the other hand the latter are not directly traced back to their determinants.

Additionally, the role of car sharing in the management of mobility of university campuses has been seldom studied. A profiling of potential car sharing users in such places is proposed in Zheng et al. (2009), showing how different living habits, personal attitudes and status influence this mode choice. A case study aiming, instead, at understanding the actions and the investments that a university has to face to sustain a car sharing program is described by Zhou (2014). At the Italian level, a study on the potential demand for car sharing in the campus of the university of Trieste is proposed in Danielis et al. (2015). Given the relatively strong presence and use of car sharing in Turin, the present work is intended to contribute to the state of the art in this ambit by profiling four groups within the community of Politecnico di Torino (the Turin technical university, covering engineering and architecture fields of study). Those groups differ concerning their awareness and use of car sharing, since they can be labelled as "early adopters" (those who are already using the service), "interested" (albeit not using the service), "not interested" and "unaware" (those that declared not knowing the service).

One notable feature of this approach is the separation between "early adopters of" and "interested in" car sharing. As far as we know, no previous study has investigated the differences between those two groups, despite the fact that such distinction can be traced back to the much debated difference between attitudes and behaviours (Sheeran, 2002), which is particularly relevant in the context of modal choices when a new transport service is proposed (Diana, 2010). While the standard approach in econometric modelling in the transport sector is to assume that attitudes are good predictors of behaviours, there 
is evidence that the same attitudes can lead to different mobility behaviours in different subjects (Anable, 2005). Studying the differences between those two groups can help in understanding to what extent interested people could actually become service users in the future.

As highlighted previously, results found in literature depict a profile of "early technology and social innovation adopter" generally associated to car sharing subscribers. Thus, many researchers decided to focus their investigation on attitudes related to car sharing on a specific convenience sample usually matching some of the above-mentioned characteristics (Costain, Ardron and Habib, 2012). The work presented in this paper follows such approach, considering a university campus as case study. At the same, the investigation of current and future mobility habits characterising such kind of communities require specific attentions in the identification of proper mobility management policies.

The next section describes the experimental activities on the field and provides some descriptive statistics of the sample. Then, travellers' profiles stemming from a data mining technique are illustrated and related to the above four groups. Some conclusions and general mobility policies are finally suggested.

\section{Dataset and highlights of descriptive statistics}

Politecnico di Torino is a technical university in the north-west of Italy and a dynamic and growing campus attracting a large number of people each day. Official numbers talk about 33,000 students enrolled in Bachelor's and Master's degree programmes (academic year 2016/17), 1,700 staff people, including professors/researchers, technicians and administrative clerks and more than 6,000 people among Ph.D. candidates, research assistants, consultants and other professional figures. The campus is located in the centre of Turin city and about 25,000 people reach the campus each day, with a clear impact on the mobility system at the larger urban level. Moreover, this site presents the previously highlighted main characteristics (collecting young educated people living in denser urban areas) that allow such university being a good case study on sharing mobility themes.

An online survey has been proposed in autumn 2016 to the staff and the students with the aim of acquiring more information on their daily journeys to reach Politecnico and on the potential interest in the provision of a car sharing service. Respondents were contacted through their institutional e-mails addresses and the survey was active for approximately a month period (18 $8^{\text {th }}$ October-11 ${ }^{\text {th }}$ November). Due to the rather explorative aim of the investigation, the questionnaire was rather lean and it took about 10 minutes to be filled. As introduction, some detailed instructions on ethics approval were proposed and precise definitions on innovative mobility modes (free float/station based car sharing, bike sharing, car pooling...) were provided too. Then, beyond a series of questions related to socioeconomic characteristics of individuals and their commuting habits, the survey specifically investigated the current use of car sharing services among the respondents. Given the focus of the research that was aimed at profiling different groups of individuals on the basis of their attitudes and general behaviours rather than studying their travel choices at the trip level, there are no detailed information on the travel patterns of respondents. 


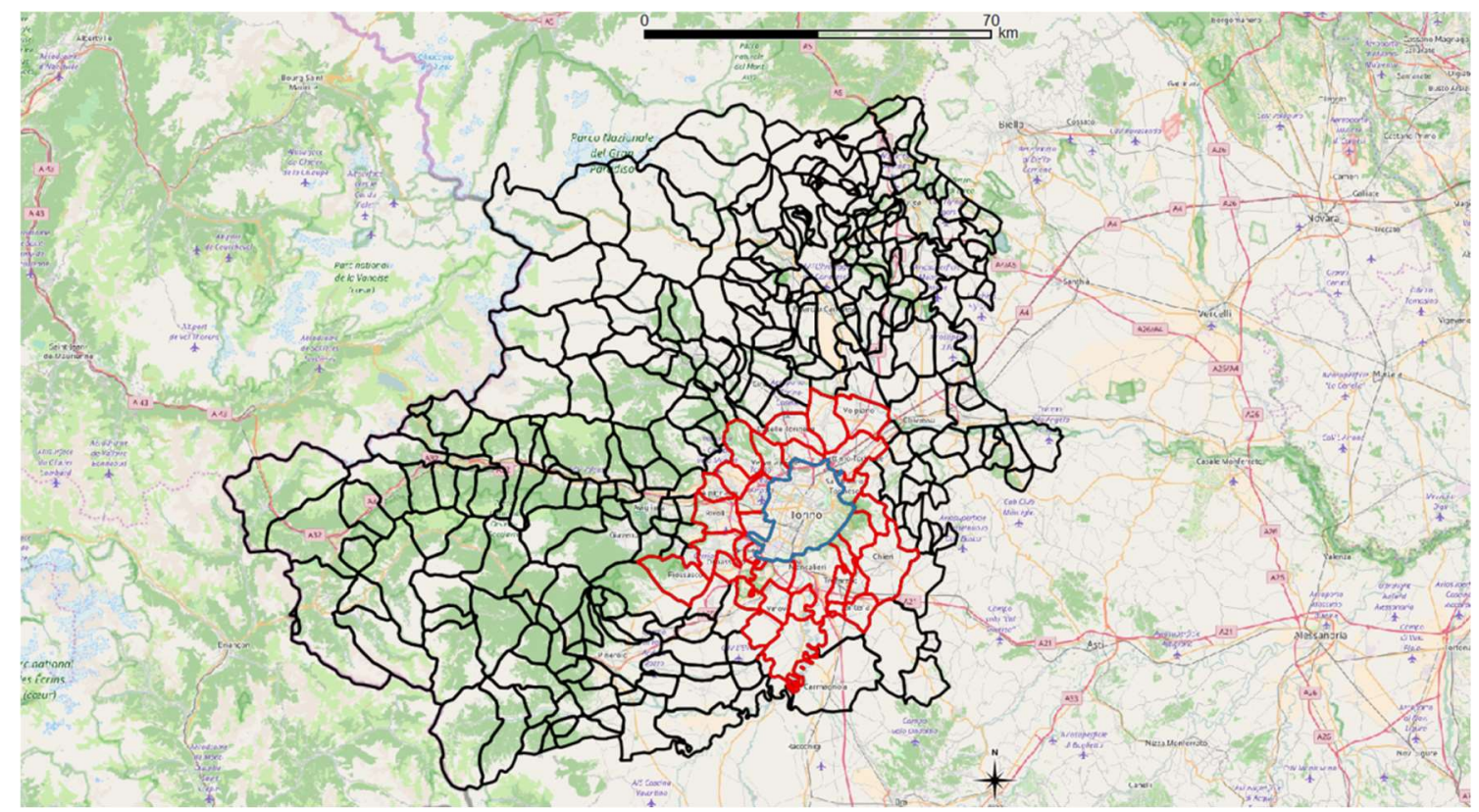

Figure 1: The map shows the borders of all the municipalities of the Turin metropolitan city (black lines), of the municipalities of "Prima cintura" (red lines) and of the city of Turin (blue line).

Source: OpenStreetMap, modified by authors.

In the following, the analysis will consider respondents who declared living in the Turin municipality, in the so-called "Prima cintura" and in the remaining municipalities composing the Turin metropolitan city (Figure 1). "Prima cintura", which is identified by the red boundaries in the map of Figure 1, collects a set of 31 municipalities located in the surrounding area of the city. The approximate distance between Politecnico and the outer edge of "Prima cintura" is $15 \mathrm{~km}$. The final dataset collects the answers provided by a sample of 1314 respondents: 1125 are students ( $86 \%$ of the sample), 189 are part of the working staff (14\%). Table 1 presents descriptive statistics of the dataset that are matched against official records of Politecnico to check the representativeness of the sample finding that both personnel and students samples are well representing their respective populations.

The analysis of the modes chosen by respondents for their journey home-Politecnico is reported in Figure 2. The distribution of occurrences for the responses to the question "Which mode (or modes) of transport do you usually use to reach Politecnico?" is placed on the left for personnel and on the right for students. Multiple answers were possible so that totals are larger than the sample size. Numbers on the top of the bars reveal that car is most used by personnel, while public transport is the usual choice of students. The values found for active modes show that riding a personal bike to reach university is relatively more popular among personnel than among students $(23 \%$ versus $18 \%$ of the sample). The situation overturns, instead, in the "Walk" case, where these shares respectively become $28 \%$ and $48 \%$. 
Table 1: Descriptive statistics on socioeconomic characteristics and commuting patterns of the sample.

\begin{tabular}{|c|c|c|c|c|}
\hline Feature & Choices & Personnel & Students & Overall \\
\hline \multirow[t]{3}{*}{ Residence } & Turin city & $68 \%$ & $74 \%$ & $73 \%$ \\
\hline & "Prima cintura" & $18 \%$ & $16 \%$ & $16 \%$ \\
\hline & Other municipalities & $14 \%$ & $10 \%$ & $11 \%$ \\
\hline \multirow[t]{5}{*}{ Age range } & $<25$ y.o. & $0 \%$ & $88 \%$ & $75 \%$ \\
\hline & $25-30$ у.о. & $4 \%$ & $11 \%$ & $10 \%$ \\
\hline & 31-40 у.о. & $24 \%$ & $1 \%$ & $4 \%$ \\
\hline & 41-50 у.о. & $31 \%$ & $0 \%$ & $5 \%$ \\
\hline & $>51$ у.о. & $41 \%$ & $0 \%$ & $6 \%$ \\
\hline \multirow[t]{5}{*}{ Enrolment year (students) } & 2016 & - & $22 \%$ & - \\
\hline & 2015 & - & $22 \%$ & - \\
\hline & 2014 & - & $18 \%$ & - \\
\hline & 2013 & - & $12 \%$ & - \\
\hline & Before 2013 & - & $26 \%$ & - \\
\hline \multirow[t]{2}{*}{ Gender } & Female & $44 \%$ & $32 \%$ & $33 \%$ \\
\hline & Male & $56 \%$ & $68 \%$ & $67 \%$ \\
\hline \multirow[t]{4}{*}{ Distance to/from Politecnico $(*)$} & $<2.5 \mathrm{~km}$ & $17 \%$ & $26 \%$ & $25 \%$ \\
\hline & $2.5-4.5 \mathrm{~km}$ & $23 \%$ & $26 \%$ & $25 \%$ \\
\hline & $4.5-10.5 \mathrm{~km}$ & $30 \%$ & $25 \%$ & $26 \%$ \\
\hline & $>10.5 \mathrm{~km}$ & $30 \%$ & $23 \%$ & $24 \%$ \\
\hline \multirow[t]{7}{*}{ Duration to/from Politecnico $\left({ }^{*}\right)$} & $<15 \min$ & $17 \%$ & $23 \%$ & $22 \%$ \\
\hline & $15-30 \mathrm{~min}$ & $46 \%$ & $35 \%$ & $37 \%$ \\
\hline & $30-45 \min$ & $18 \%$ & $17 \%$ & $17 \%$ \\
\hline & $45-60 \mathrm{~min}$ & $13 \%$ & $15 \%$ & $15 \%$ \\
\hline & $60-75 \min$ & $4 \%$ & $6 \%$ & $5 \%$ \\
\hline & $75-90 \mathrm{~min}$ & $2 \%$ & $3 \%$ & $3 \%$ \\
\hline & $>90 \mathrm{~min}$ & $0 \%$ & $1 \%$ & $1 \%$ \\
\hline
\end{tabular}

(*) Distance and duration were self-stated by respondents. 


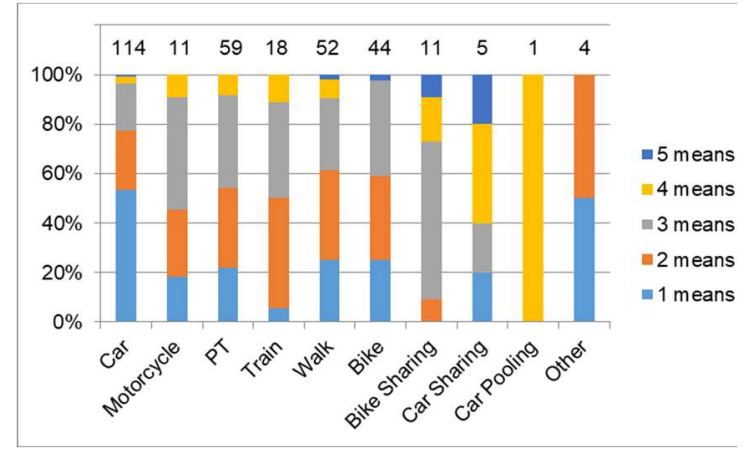

(a)

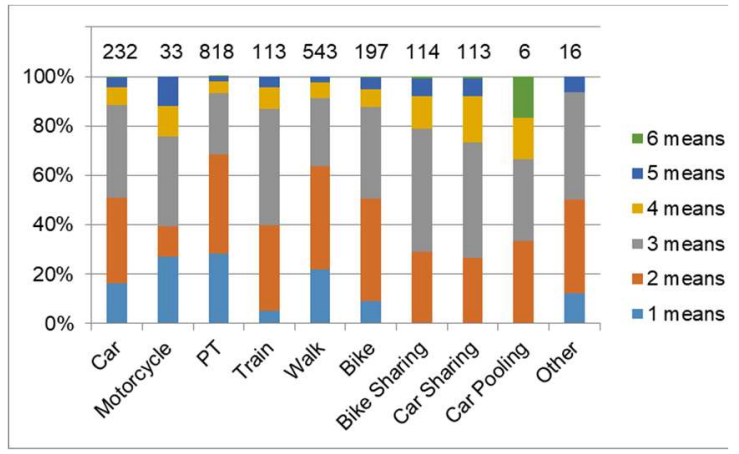

(b)

Figure 2 Frequencies of use of different modes to reach the campus (number on the top of each bar) for personnel (a) and for students (b). Different colours show the number of used modes.

Focusing on bike sharing and car sharing, they are mainly chosen by students, while rather low occurrences are seen in Figure 2(a) for personnel. The flexibility of the sharing approach is certainly appealing for the students, having in mind that a high number of those attending Politecnico come from outside Piemonte region (58\% according to official numbers) and therefore might not have access to a personal car. Moreover, the possibility of using the personal smart card provided by the university also as membership card for bike sharing (but also as a public transport pass), certainly helps these modal choices.

To better understand the actual multimodality patterns for commuting trips and therefore the potential role of car sharing, Figure 2 shows how many different transport modes are used for commuting when any given mode is indicated by the respondents. For example, staff commuting by car tends to do not use other modes (light blue colour in the leftmost bar of Figure 2(a)). In contrast, shared mobility options for students are always used in combination with other modes (rightmost bars of Figure 2(b)), while the corresponding results for staff lack statistical significance due to an insufficient number of observations. Shared mobility options are not perceived as a "unique" mode of transport, but rather as a "multimodal" option, confirming that these users tend to increase their attitudes to combine different transport modes such as bikes and walking (Kopp, Gerike and Axhausen, 2015; Clewlow, 2016). Car sharing could be seen for example as an alternative to public transport or to active modes in certain conditions, such as a rainy day or in case of disruptions.

As previously introduced, one of the goals of the survey was to assess the interest in car sharing in the campus. This was addressed through a specific question: "Would you be interest in registering for a car sharing service?" with possible answers "Yes", "No", "I do not know the service" and "I am already using car sharing". Those four answers identify, as we will call them in the following, "groups" of individuals, previously labelled in the introduction as "Early adopters", "Interested", "Not interested" and "Unaware". In the former two cases, the motivation behind its actual or potential use was investigated too. Available choices for early adopters were "Economical convenience", "To move in the city", "To reach university" and "To connect with other modes", while, for interested people, possible answers were "Economical convenience", "Near home parking", "Near university parking" and "To connect with other modes". 
Table 2 shows the cross tabulation of the answers to such questions. Looking at the row totals in the third column, the students sample contains both more interested and much more car sharing users, while car sharing is less attractive for staff. This confirms the opportunity of focusing the research on car sharing attitudes on such community. It must be recalled that the numbers in Table 2 cannot be derived from those in Figure 2 since, in the first case, the focus was on the journey home-university, while, in the latter, a more general attitude is investigated.

Table 2: Cross-tabulation of responses related to car sharing use and interest with their respective motivations. The sum in each row is larger than the sample size since multiple choices were possible.

\begin{tabular}{|c|c|c|c|c|c|c|c|c|}
\hline & \multicolumn{8}{|c|}{ Motivation } \\
\hline & \multicolumn{2}{|c|}{$\begin{array}{c}\text { Interested } \\
\text { in car sharing? }\end{array}$} & $\begin{array}{l}\text { Economical } \\
\text { convenience }\end{array}$ & $\begin{array}{l}\text { To connect } \\
\text { with other } \\
\text { modes }\end{array}$ & $\begin{array}{l}\text { To move } \\
\text { in the city }\end{array}$ & $\begin{array}{l}\text { To reach } \\
\text { university }\end{array}$ & $\begin{array}{c}\text { Near home } \\
\text { parking }\end{array}$ & $\begin{array}{c}\text { Near } \\
\text { university } \\
\text { parking }\end{array}$ \\
\hline \multirow[t]{3}{*}{ Pers. } & $\begin{array}{c}\text { Already } \\
\text { using }\end{array}$ & $17(9 \%)$ & 4 & 3 & 12 & 4 & n.a. & n.a. \\
\hline & Yes & $55(29 \%)$ & 44 & 14 & n.a. & n.a. & 29 & 25 \\
\hline & No & $90(48 \%)$ & n.a. & n.a. & n.a. & n.a. & n.a. & n.a. \\
\hline \multirow{5}{*}{ Stud. } & $\begin{array}{c}\text { Service } \\
\text { unknown } \\
\text { Tot. }\end{array}$ & $\begin{array}{c}27(14 \%) \\
189(100 \%)\end{array}$ & n.a. & n.a. & n.a. & n.a. & n.a. & n.a. \\
\hline & $\begin{array}{l}\text { Already } \\
\text { using }\end{array}$ & $309(27 \%)$ & 114 & 39 & 277 & 39 & n.a. & n.a. \\
\hline & Yes & $437(39 \%)$ & 404 & 100 & n.a. & n.a. & 240 & 215 \\
\hline & No & $256(23 \%)$ & n.a. & n.a. & n.a. & n.a. & n.a. & n.a. \\
\hline & $\begin{array}{c}\text { Service } \\
\text { unknown } \\
\text { Tot. }\end{array}$ & $\begin{array}{c}123(11 \%) \\
1125(100 \%)\end{array}$ & n.a. & n.a. & n.a. & n.a. & n.a. & n.a. \\
\hline
\end{tabular}

n.a.: not asked.

Concerning the motivation behind the actual use of car sharing, the most popular one is "To move in the city", while the main reason leading the interest in the use of car sharing is "Economical convenience", followed by "Near home parking", "Near university parking" and "To connect with other modes". However, a noticeable difference in relative values between students and staff is found for the "Economical convenience" aspect (404/437 corresponds to $92 \%$, while $44 / 55$ to $80 \%$ ), in line with the tighter budget constraints of students. These results show that potential choice of car sharing seems to be mainly pushed by economic reasons, mainly seen as less costs compared to traditional cars maintenance, as in many literature works (Ciari and Axhausen, 2012; Clewlow, 2016).

\section{Respondents profiles through co-clustering}

\subsection{Data preparation.}

In the previous section, descriptive statistics have helped in identifying the consistency of the four main groups of respondents in relation with their car sharing attitudes and use. The objective now is to better study these groups by checking whether individuals belonging to each one are characterised by different combinations of both personal and 
situational features. More in detail, three main classes of variables are considered to this effect: socioeconomic characteristics of the respondent, characteristics of the commuting trip and satisfaction ratings related to specific aspects of the commuting trip. Concerning the latter two kinds of variables, it should be acknowledged that travellers' habits and views cannot be observed by exclusively focusing on the systematic mobility component, as done in the present research. Nevertheless, the focus of the present research is on the opportunities given by car sharing services in relation with a large mobility attractor such as university campuses, rather than to serve the mobility needs of a general population.

Concerning data preparation, categories related to "Age range" and "Duration" as shown in Table 1 are the same as in the survey questionnaire, while those pertaining to "Distance" have been derived from a continuous variable by defining thresholds such that the corresponding categories roughly have the same number of individuals. As previously mentioned, travel distances and times were self-reported by respondents. Since we are referring to the commuting trip, we can assume that this information is enough reliable. Compared to Figure 2, categories related to mode choice were aggregated into four main types: public transport "PT" (including train and public transport), individual modes "IM" (car, motorcycle and car pooling), bike sharing "BS" and active modes "AC" (walk and bike). "Car sharing" answers were not considered in this variable since they already identify the "Early adopters" group. Finally, satisfaction ratings were also consolidated into two classes ("Unsatisfied" and "Satisfied") from the 4-point original scale which ranged from "Unsatisfied" to "Not very satisfied", "Rather satisfied" and "Very satisfied".

To sum up, the three categories of variables considered in the analysis include the following features:

- Socioeconomic (residence, age range - only personnel, enrolment year - only students, gender)

- Travel related (distance, duration, modes used)

- Satisfaction (journey cost, journey duration, parking availability).

\subsection{Method of analysis.}

A preliminary analysis was made to understand if the four above groups significantly differ in any of the considered features. Table 3 depicts the results for the personnel and Table 4 for students. The second column reveals as car sharing users are mainly living in the municipality of Turin and, therefore, have shorter commute trips than the average and tend to walk and bike more than the average to go to work or to attend lessons. Quite interestingly, early adopters among staff are mainly males, but such gender difference is more blurred among students. Older workers tend to be more unaware of car sharing services and they are the most satisfied with the cost of their commute trip (last column).

The following step in the analysis would be to understand if such features can be good predictors of group membership. Rather than studying the individual contribution of each feature to a given outcome in terms of group membership through a modelling approach based on RP and/or SP data, it seems more important to understand how the combination of different features is more frequently encountered within some groups. An exploratory analysis of this kind can help in selecting which variables are more characterising the different groups and such information can be later used in a more confirmatory analysis to specify a multivariate model. The present paper therefore takes a complementary approach compared to the bulk of literature that models either revealed or stated choices 
pertaining to car sharing through dependence techniques to trace them back to socioeconomic or attitudinal factors. Indeed, so far such models have given mixed results e.g. in terms of substitution versus complementarity rates between car sharing and other means (Ceccato and Diana, 2019). There is thus a need to better understand how both personal and travel-related characteristics can jointly interact to shape mobility behaviours, and considering personal profiles based on data rather than developing linear (or linear in the parameters) models can be of help to advance on this issue.

Table 3: Relative frequencies of features characterising the four groups of respondents related to car sharing interest for the personnel.

\begin{tabular}{|c|c|c|c|c|}
\hline Variables & Early adopters & Interested & Not interested & Unaware \\
\hline \multicolumn{5}{|l|}{ Residence } \\
\hline Turin city & $\mathbf{9 4} \%$ & $\mathbf{5 8} \%$ & $66 \%$ & $78 \%$ \\
\hline "Prima cintura" & $6 \%$ & $24 \%$ & $22 \%$ & $4 \%$ \\
\hline Other municipalities & $0 \%$ & $18 \%$ & $12 \%$ & $18 \%$ \\
\hline \multicolumn{5}{|l|}{ Age range } \\
\hline 25-30 у.о. & $12 \%$ & $2 \%$ & $3 \%$ & $7 \%$ \\
\hline $31-40$ y.o. & $24 \%$ & $31 \%$ & $21 \%$ & $19 \%$ \\
\hline $41-50$ y.o. & $35 \%$ & $34 \%$ & $28 \%$ & $33 \%$ \\
\hline$>51$ y.o. & $29 \%$ & $33 \%$ & $48 \%$ & $41 \%$ \\
\hline \multicolumn{5}{|l|}{ Gender } \\
\hline Female & $18 \%$ & $44 \%$ & $51 \%$ & $41 \%$ \\
\hline \multicolumn{5}{|c|}{ Distance to/from Politecnico } \\
\hline$<2.5 \mathrm{~km}$ & $30 \%$ & $13 \%$ & $17 \%$ & $19 \%$ \\
\hline $2.5-4.5 \mathrm{~km}$ & $35 \%$ & $18 \%$ & $21 \%$ & $22 \%$ \\
\hline $4.5-10.5 \mathrm{~km}$ & $35 \%$ & $31 \%$ & $29 \%$ & $33 \%$ \\
\hline$>10.5 \mathrm{~km}$ & $0 \%$ & $38 \%$ & $\mathbf{3 3} \%$ & $26 \%$ \\
\hline \multicolumn{5}{|c|}{ Duration to/from Politecnico } \\
\hline$<15 \min$ & $35 \%$ & $11 \%$ & $20 \%$ & $11 \%$ \\
\hline $15-30 \mathrm{~min}$ & $\mathbf{5 9} \%$ & $44 \%$ & $44 \%$ & $\mathbf{5 2} \%$ \\
\hline $30-45 \min$ & $6 \%$ & $18 \%$ & $21 \%$ & $15 \%$ \\
\hline $45-60 \mathrm{~min}$ & $0 \%$ & $16 \%$ & $12 \%$ & $18 \%$ \\
\hline $60-75 \min$ & $0 \%$ & $7 \%$ & $2 \%$ & $4 \%$ \\
\hline $75-90 \min$ & $0 \%$ & $4 \%$ & $1 \%$ & $0 \%$ \\
\hline \multicolumn{5}{|l|}{ Modes used } \\
\hline PT & $47 \%$ & $44 \%$ & $34 \%$ & $44 \%$ \\
\hline $\mathrm{IM}$ & $47 \%$ & $73 \%$ & $64 \%$ & $56 \%$ \\
\hline $\mathrm{BS}$ & $18 \%$ & $5 \%$ & $4 \%$ & $4 \%$ \\
\hline $\mathrm{AC}$ & $71 \%$ & $45 \%$ & $39 \%$ & $37 \%$ \\
\hline Journey cost & & & & \\
\hline
\end{tabular}


European Transport $\backslash$ Trasporti Europei (2020) Issue 79, Paper n 1, ISSN 1825-3997

\begin{tabular}{lcccc}
\hline Unsatisfied & $18 \%$ & $42 \%$ & $18 \%$ & $33 \%$ \\
$\begin{array}{l}\text { Journey duration } \\
\text { Unsatisfied }\end{array}$ & $18 \%$ & $36 \%$ & $21 \%$ & $37 \%$ \\
$\begin{array}{l}\text { Parking availability } \\
\text { Unsatisfied }\end{array}$ & $29 \%$ & $22 \%$ & $21 \%$ & $30 \%$ \\
\hline
\end{tabular}

Table 4: Relative frequencies of features characterising the four groups of respondents related to car sharing interest for the students.

\begin{tabular}{|c|c|c|c|c|}
\hline Variables & Early adopters & Interested & Not interested & Unaware \\
\hline \multicolumn{5}{|l|}{ Residence } \\
\hline Turin city & $94 \%$ & $74 \%$ & $61 \%$ & $49 \%$ \\
\hline "Prima cintura" & $5 \%$ & $16 \%$ & $23 \%$ & $29 \%$ \\
\hline Other municipalities & $1 \%$ & $10 \%$ & $16 \%$ & $22 \%$ \\
\hline \multicolumn{5}{|l|}{ Enrolment year } \\
\hline 2016 & $11 \%$ & $29 \%$ & $20 \%$ & $34 \%$ \\
\hline 2015 & $24 \%$ & $22 \%$ & $21 \%$ & $20 \%$ \\
\hline 2014 & $23 \%$ & $13 \%$ & $18 \%$ & $19 \%$ \\
\hline 2013 & $15 \%$ & $10 \%$ & $12 \%$ & $11 \%$ \\
\hline Before 2013 & $27 \%$ & $26 \%$ & $29 \%$ & $17 \%$ \\
\hline \multicolumn{5}{|l|}{ Gender } \\
\hline Female & $29 \%$ & $33 \%$ & $31 \%$ & $37 \%$ \\
\hline \multicolumn{5}{|c|}{ Distance to/from Politecnico } \\
\hline$<2.5 \mathrm{~km}$ & $41 \%$ & $26 \%$ & $16 \%$ & $13 \%$ \\
\hline $2.5-4.5 \mathrm{~km}$ & $31 \%$ & $25 \%$ & $24 \%$ & $20 \%$ \\
\hline $4.5-10.5 \mathrm{~km}$ & $23 \%$ & $25 \%$ & $27 \%$ & $24 \%$ \\
\hline$>10.5 \mathrm{~km}$ & $5 \%$ & $24 \%$ & $34 \%$ & $42 \%$ \\
\hline \multicolumn{5}{|c|}{ Duration to/from Politecnico } \\
\hline$<15 \min$ & $38 \%$ & $21 \%$ & $16 \%$ & $11 \%$ \\
\hline $15-30 \mathrm{~min}$ & $40 \%$ & $36 \%$ & $34 \%$ & $24 \%$ \\
\hline $30-45 \mathrm{~min}$ & $15 \%$ & $17 \%$ & $15 \%$ & $23 \%$ \\
\hline $45-60 \mathrm{~min}$ & $7 \%$ & $16 \%$ & $19 \%$ & $22 \%$ \\
\hline $60-75 \min$ & $1 \%$ & $4 \%$ & $10 \%$ & $13 \%$ \\
\hline $75-90 \min$ & $0 \%$ & $4 \%$ & $5 \%$ & $7 \%$ \\
\hline$>90 \min$ & $0 \%$ & $2 \%$ & $1 \%$ & $2 \%$ \\
\hline \multicolumn{5}{|l|}{ Modes used } \\
\hline PT & $66 \%$ & $81 \%$ & $79 \%$ & $83 \%$ \\
\hline IM & $15 \%$ & $24 \%$ & $25 \%$ & $30 \%$ \\
\hline BS & $13 \%$ & $10 \%$ & $9 \%$ & $7 \%$ \\
\hline $\mathrm{AC}$ & $69 \%$ & $\mathbf{5 3} \%$ & $\mathbf{5 7} \%$ & $49 \%$ \\
\hline
\end{tabular}




\begin{tabular}{lcccc}
\hline Journey cost & & & \\
Unsatisfied & $31 \%$ & $35 \%$ & $38 \%$ & $46 \%$ \\
$\begin{array}{l}\text { Journey duration } \\
\text { Unsatisfied }\end{array}$ & $30 \%$ & $46 \%$ & $43 \%$ & $\mathbf{5 6} \%$ \\
$\begin{array}{l}\text { Parking availability } \\
\text { Unsatisfied }\end{array}$ & & & & \\
\hline
\end{tabular}

An innovative cluster analysis approach will be used to this effect. This technique is popular in data mining and it is used to partition into different groups a collection of elements defined through certain characteristics (in this case, the above features). These groups are the so called "clusters": the main goal of the technique is to maximise the homogeneity of the elements within each cluster and the heterogeneity between the various clusters. Some works are found in literature applying this technique to different domains of transport engineering such as tours classification (Pirra and Diana, 2016) or transit quality evaluation (de Oña et al., 2014; de Oña, de Oña and López, 2016). However, an innovative parameter-less method named "multi-view co-clustering", is adopted here (Ienco et al., 2013; Pirra and Pensa, 2019). Classical co-clustering computes a partition of objects and a partition of features simultaneously, thus providing meaningful clusters of objects with a useful interpretation given by the grouping on features (Dhillon, Mallela and Modha, 2003): this approach is different from clustering features and objects separately, since it adopts an objective function whose optimization takes into account both the object partition and the feature partition. In addition, the problem of heterogonous (multi-view) data clustering is addressed, where the same set of objects can be represented within different feature views or spaces. The multi-view co-clustering approach, instead, consists in clustering the set of objects according to multiple partitions on the spaces of features. Every feature space is partitioned according to a unique object partition, while the object partition is influenced by multiple feature space partitions simultaneously.

Moreover, the multi-view co-clustering approach adopted here has another great advantage against classic clustering (e.g., k-means) and co-clustering techniques (Tan, Steinbach and Kumar, 2005): the algorithm automatically determines the number of clusters. This result is made possible by the use of the Goodman and Kruskal $\tau$ measure (Goodman and Kruskal, 1954), as the objective function to be optimized. In this way, any specific information is requested by the algorithm before its application to the dataset and the results are obtained through a "letting the data speak" approach. The current dataset was simply pre-processed to convert the categorical variables listed in Table 3 and Table 4 into binary (dummy) ones, one dummy for each category, which is the input required by the algorithm. The approach proposed here is not influenced by the kind of the sample under study or by the variables considered. For the mathematical details and the complete description of the multi-view co-clustering algorithm, the reader is referred to Ienco et al. (2013).

\subsection{Experimental design.}

In the following, students and personnel are separately studied to better highlight the potential differences, or similarities, between these two groups. The co-clustering 
algorithm was run three times for both students and personnel, each time considering a different subset of variables (socioeconomic, travel related, satisfaction) to build the clusters. Separately considering these subsets, rather than joining them all in a unique analysis, can be useful to understand if any of them is sufficient to identify the membership to any of the four groups. Group means for all variables were then computed for both clustering variables (one of the three above subsets) and the remaining variables (the other two subsets), while the proportion of individuals belonging to each of the four car sharing groups and falling into each cluster was also computed.

Table 5: Experimental design with resulting clusters.

\begin{tabular}{|c|c|c|c|c|}
\hline & $\begin{array}{l}\text { Clustering } \\
\text { variables }\end{array}$ & Socioeconomics (E) & $\begin{array}{c}\text { Travel } \\
\text { related }(T)\end{array}$ & $\begin{array}{c}\text { Satisfaction } \\
\text { ratings (S) }\end{array}$ \\
\hline Pers. & $\begin{array}{c}\text { Early Adopters } \\
\text { (EA) } \\
\text { Interested } \\
\text { (IN) } \\
\text { Not interested } \\
\text { (NI) } \\
\text { Unaware } \\
\text { (UN) } \\
\text { Neutral } \\
\text { (X, X1 and X2) }\end{array}$ & $\begin{array}{l}\text { Clus_PE_E_EA } \\
(\overline{7} 1 \mathrm{obs} .) \\
\text { Clus_PE_E_IN } \\
(\overline{34} \mathrm{obs} .) \\
\text { Clus_PE_E_NI } \\
(\overline{52} \text { obs. }) \\
\text { Clus_PE_E_UN } \\
(\overline{3} 2 \mathrm{obs} .)\end{array}$ & 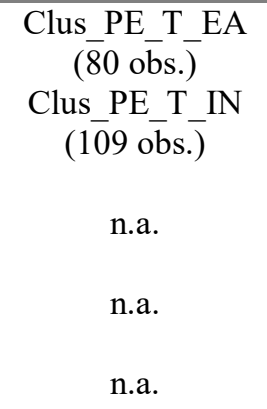 & $\begin{array}{l}\text { n.a. } \\
\text { Clus_PE_S_IN } \\
(\overline{95} \text { obs. }) \\
\text { Clus_PE_S_NI } \\
\quad(\overline{94} \text { obs. })\end{array}$ \\
\hline Stud. & $\begin{array}{c}\text { Early Adopters } \\
\text { (EA) } \\
\text { Interested } \\
\text { (IN) } \\
\text { Not interested } \\
\text { (NI) } \\
\text { Unaware } \\
\text { (UN) } \\
\text { Neutral } \\
\text { (X, X1 and X2) }\end{array}$ & $\begin{array}{c}\text { n.a. } \\
\text { Clus_ST_E_UN } \\
(155 \text { obs. }) \\
\text { Clus_ST_E_X1 (414 obs.) \& } \\
\text { Clus_ST_E_X2 (282 obs.) }\end{array}$ & $\begin{array}{c}\text { n.a. } \\
\underset{(363 \text { obs. })}{\text { Clus_ST_T_NN* }} \\
\underset{(421 \text { obs. })}{\text { Clus_ST_T_X }}\end{array}$ & $\begin{array}{l}\text { n.a. } \\
\text { n.a. } \\
\text { Clus_ST_S_X } \\
(521 \text { obs. })\end{array}$ \\
\hline
\end{tabular}

* Students either not interested or unaware of car sharing are equally over-represented in this cluster, which is therefore not specifically assigned to any of these two groups and is labelled with a final "NN"; n.a.: not available.

Clusters were then labelled considering which of the four groups was relatively most represented inside the cluster itself. Each cluster is then given a label, whose last two letters indicate the prevailing group. However, please note that no cluster is exactly replicating any group, such that it is not possible to directly compare figures in Table 5 with those in Table 2. As mentioned in section 3.2, the co-clustering technique is not predetermining the number of clusters. As a result, less than four clusters were created in some instances, while in other cases the proportion of the groups defined inside clusters was not distinguishable from that of the overall sample.

Table 5 is showing the overall experimental design, reporting for each cluster the assigned labels and the number of observations. In the following sections, these clusters are more systematically illustrated in order to delineate some car sharing users and nonusers' profiles in the context of Politecnico di Torino, separately considering personnel and students datasets. The observed relative frequencies of the various features will be 
reported in Table 6 and Table 7 and can be compared with the relative frequencies of the whole sample in Table 3 and in Table 4 . The bold numbers in the tables highlight the variables with highest occurrence in the clusters found in the different runs of the algorithm. Moreover, the last four rows of Table 6 and Table 7 show the proportion of subjects belonging to the four groups in order to appreciate to which extent the resulting clusters are discriminating different behaviours and attitudes related to car sharing (bold numbers).

\subsection{Results: personnel cluster.}

By jointly considering the rows of Table 5 referring to the personnel it can be concluded that the clustering analysis was rather successful in singling out the group of early adopters and of interested people, despite the relatively low sample size, irrespective of the chosen clustering variables.

More specifically, four different clusters of respondents were extracted when using socioeconomic variables for classifying the staff (from second to fifth column in Table 6) which can be relatively straightforwardly matched with the already known four groups. Confirming results from Table 3, early adopters are living more in the Turin municipality than the average (Clus_PE_E_EA). They are clearly more using active means than the average and are (therefore?) rather satisfied with the cost and time of their commuting trips. Concerning the latter aspect, the most satisfied are those belonging to Clus_PE_E_UN, which are older men living mainly in the Turin municipality.

Interested people are younger females living in the outer part of the metropolitan city (Clus_PE_E_IN), where such service is not yet available. On the other hand, older staff living mainly in "Prima Cintura" (Clus_PE_E_NI) is not interested in car sharing. The latter socioeconomic group is also using more car than the average and it is likely to have a parking place available at work (almost $90 \%$ is satisfied with parking availability), so that the effectiveness of car sharing as an alternative to its actual mobility habits is probably very low. On a brighter side, marketing actions to promote car sharing which are targeted to the above mentioned Clus_PE_E_IN cluster could have the potential to substitute a good amount of vehicle kilometres travelled, since this cluster is more frequently commuting by car compared to the average and for longer distances.

The application of the co-clustering technique generates two clusters when considering either travel-related or satisfaction items as clustering variables. Therefore, it was not possible to single out one cluster for each group as in the previous case. This analysis is complementary to the previous one and aims at understanding whether it is possible to distinguish early adopters and interested people solely on the basis of either the characteristics of their commuting trip or the related satisfaction ratings. The interest of this approach lies, for example, in the possibility of identifying target groups for car sharing marketing actions on the basis of passively collected or anonymised data, which are more and more widely available with the diffusion of smartphones and related apps. When clustering through travel-related variables (sixth and seventh column in Table 6), the proportion of the four groups within the two clusters is not significantly varying. However, early adopters can be more probably found among commuters by bike and active means which are conversely using cars less than the average (Clus_PE_T_EA), whereas those interested in car sharing are using more the car and less active means (Clus_PE_T_IN). As discussed in the introduction, observed differences in the characteristics of individuals in those two clusters are also probably reflecting a difference 
between those that have an only positive attitude towards the service, but little intention to use it, and really potential users. Finally and as a complement to the above analysis, the two clusters obtained in the last two columns of Table 6 show that travel-related satisfaction ratings (that could be quickly elicited through instant polls while people are travelling) can fairly discriminate between those interested (Clus_PE_S_IN) and those not interested (Clus_PE_S_NI) in the car sharing service. 
European Transport \Trasporti Europei (2020) Issue 79, Paper n 1, ISSN 1825-3997

Table 6: Cluster profiling (relative frequencies of features) for personnel when the clustering variables are socioeconomics, travel related or satisfaction ratings.

\begin{tabular}{|c|c|c|c|c|c|c|c|c|}
\hline Variables & Clus_PE_E_EA & Clus_PE_E_NI & Clus_PE_E_IN & Clus_PE_E_UN & Clus_PE_T_IN & Clus_PE_T_EA & Clus_PE_S_IN & Clus_PE_S_NI \\
\hline \multicolumn{9}{|l|}{ Residence } \\
\hline Turin city & $93 \%$ & $35 \%$ & $\mathbf{5 0} \%$ & $84 \%$ & $44 \%$ & $100 \%$ & $\mathbf{5 9} \%$ & $77 \%$ \\
\hline "Prima cintura" & $0 \%$ & $48 \%$ & $15 \%$ & $16 \%$ & $32 \%$ & $0 \%$ & $21 \%$ & $16 \%$ \\
\hline $\begin{array}{l}\text { Other } \\
\text { municipalities }\end{array}$ & $7 \%$ & $17 \%$ & $35 \%$ & $0 \%$ & $24 \%$ & $0 \%$ & $20 \%$ & $7 \%$ \\
\hline \multicolumn{9}{|l|}{ Age range } \\
\hline 25-30 у.о. & $11 \%$ & $0 \%$ & $0 \%$ & $0 \%$ & $4 \%$ & $5 \%$ & $5 \%$ & $3 \%$ \\
\hline $31-40$ у.о. & $23 \%$ & $2 \%$ & $82 \%$ & $0 \%$ & $23 \%$ & $25 \%$ & $24 \%$ & $23 \%$ \\
\hline $41-50$ у.о. & $66 \%$ & $4 \%$ & $15 \%$ & $16 \%$ & $26 \%$ & $39 \%$ & $29 \%$ & $33 \%$ \\
\hline > 51 у.о. & $0 \%$ & $\mathbf{9 4} \%$ & $3 \%$ & $84 \%$ & $48 \%$ & $31 \%$ & $41 \%$ & $40 \%$ \\
\hline \multicolumn{9}{|l|}{ Gender } \\
\hline Female & $35 \%$ & $\mathbf{5 4} \%$ & $91 \%$ & $0 \%$ & $48 \%$ & $40 \%$ & $47 \%$ & $41 \%$ \\
\hline \multicolumn{9}{|l|}{ Distance to/from } \\
\hline \multicolumn{9}{|l|}{ Politecnico } \\
\hline$<2.5 \mathrm{~km}$ & $24 \%$ & $4 \%$ & $18 \%$ & $22 \%$ & $1 \%$ & $39 \%$ & $15 \%$ & $19 \%$ \\
\hline $2.5-4.5 \mathrm{~km}$ & $27 \%$ & $12 \%$ & $12 \%$ & $38 \%$ & $3 \%$ & $48 \%$ & $17 \%$ & $27 \%$ \\
\hline $4.5-10.5 \mathrm{~km}$ & $37 \%$ & $29 \%$ & $24 \%$ & $28 \%$ & $44 \%$ & $13 \%$ & $27 \%$ & $34 \%$ \\
\hline$>10.5 \mathrm{~km}$ & $13 \%$ & $56 \%$ & $47 \%$ & $13 \%$ & $\mathbf{5 2} \%$ & $1 \%$ & $41 \%$ & $20 \%$ \\
\hline \multicolumn{9}{|l|}{ Duration to/from } \\
\hline \multicolumn{9}{|l|}{ Politecnico } \\
\hline$<15 \min$ & $24 \%$ & $7 \%$ & $6 \%$ & $31 \%$ & $2 \%$ & $39 \%$ & $10 \%$ & $26 \%$ \\
\hline $15-30 \mathrm{~min}$ & $\mathbf{5 5} \%$ & $33 \%$ & $41 \%$ & $\mathbf{5 3} \%$ & $37 \%$ & $\mathbf{5 9} \%$ & $39 \%$ & $\mathbf{5 3} \%$ \\
\hline $30-45 \mathrm{~min}$ & $13 \%$ & $29 \%$ & $18 \%$ & $13 \%$ & $29 \%$ & $3 \%$ & $24 \%$ & $12 \%$ \\
\hline $45-60 \min$ & $6 \%$ & $21 \%$ & $29 \%$ & $0 \%$ & $23 \%$ & $0 \%$ & $19 \%$ & $7 \%$ \\
\hline $60-75 \min$ & $1 \%$ & $6 \%$ & $6 \%$ & $3 \%$ & $6 \%$ & $4 \%$ & $6 \%$ & $1 \%$ \\
\hline
\end{tabular}


European Transport $\backslash$ Trasporti Europei (2020) Issue 79, Paper n 1, ISSN 1825-3997

\begin{tabular}{|c|c|c|c|c|c|c|c|c|}
\hline $75-90 \min$ & $1 \%$ & $4 \%$ & $0 \%$ & $0 \%$ & $3 \%$ & $0 \%$ & $2 \%$ & $1 \%$ \\
\hline \multicolumn{9}{|l|}{ Modes used } \\
\hline PT & $41 \%$ & $44 \%$ & $38 \%$ & $31 \%$ & $43 \%$ & $35 \%$ & $48 \%$ & $31 \%$ \\
\hline IM & $49 \%$ & $81 \%$ & $71 \%$ & $63 \%$ & $84 \%$ & $36 \%$ & $69 \%$ & $\mathbf{5 9} \%$ \\
\hline BS & $11 \%$ & $0 \%$ & $6 \%$ & $3 \%$ & $0 \%$ & $14 \%$ & $9 \%$ & $2 \%$ \\
\hline $\mathrm{AC}$ & $\mathbf{5 9} \%$ & $29 \%$ & $38 \%$ & $38 \%$ & $23 \%$ & $71 \%$ & $38 \%$ & $49 \%$ \\
\hline \multicolumn{9}{|l|}{ Journey cost } \\
\hline Unsatisfied & $18 \%$ & $38 \%$ & $35 \%$ & $19 \%$ & $39 \%$ & $11 \%$ & $\mathbf{5 4} \%$ & $0 \%$ \\
\hline \multicolumn{9}{|c|}{ Journey duration } \\
\hline Unsatisfied & $21 \%$ & $38 \%$ & $38 \%$ & $13 \%$ & $43 \%$ & $6 \%$ & $\mathbf{5 5} \%$ & $0 \%$ \\
\hline \multicolumn{9}{|c|}{ Parking availability } \\
\hline Unsatisfied & $25 \%$ & $13 \%$ & $21 \%$ & $38 \%$ & $18 \%$ & $30 \%$ & $46 \%$ & $0 \%$ \\
\hline \multicolumn{9}{|l|}{ Car sharing } \\
\hline EA & $16 \%$ & $4 \%$ & $3 \%$ & $9 \%$ & $5 \%$ & $14 \%$ & $8 \%$ & $10 \%$ \\
\hline IN & $27 \%$ & $25 \%$ & $41 \%$ & $28 \%$ & $33 \%$ & $24 \%$ & $35 \%$ & $23 \%$ \\
\hline NI & $39 \%$ & $61 \%$ & $47 \%$ & $44 \%$ & $48 \%$ & $47 \%$ & $40 \%$ & $\mathbf{5 5} \%$ \\
\hline UN & $18 \%$ & $10 \%$ & $9 \%$ & $19 \%$ & $14 \%$ & $15 \%$ & $17 \%$ & $12 \%$ \\
\hline
\end{tabular}


European Transport \Trasporti Europei (2020) Issue 79, Paper n 1, ISSN 1825-3997

Table 7: Cluster profiling (relative frequencies of features) for students when the clustering variables are socioeconomics, travel related or satisfaction ratings.

\begin{tabular}{|c|c|c|c|c|c|c|c|c|c|}
\hline Variables & Clust_ST_E_X1 & Clus_ST_E_X2 & Clus_ST_E_EA & Clus_ST_E_UN & Clus_ST_T_X & Clus_ST_T_NN & Clus_ST_T_EA & Clus_ST_S_EA & Clus_ST_S_X \\
\hline \multicolumn{10}{|l|}{ Residence } \\
\hline Turin city & $65 \%$ & $80 \%$ & $100 \%$ & $37 \%$ & $\mathbf{9 5} \%$ & $24 \%$ & $100 \%$ & $86 \%$ & $60 \%$ \\
\hline "Prima cintura" & $8 \%$ & $20 \%$ & $0 \%$ & $\mathbf{5 9} \%$ & $5 \%$ & $44 \%$ & $0 \%$ & $9 \%$ & $25 \%$ \\
\hline $\begin{array}{l}\text { Other } \\
\text { municipalities }\end{array}$ & $26 \%$ & $0 \%$ & $0 \%$ & $3 \%$ & $0 \%$ & $31 \%$ & $0 \%$ & $5 \%$ & $16 \%$ \\
\hline \multicolumn{10}{|l|}{ Enrolment year } \\
\hline 2016 & $7 \%$ & $41 \%$ & $0 \%$ & $70 \%$ & $27 \%$ & $20 \%$ & $20 \%$ & $\mathbf{2 5} \%$ & $17 \%$ \\
\hline 2015 & $12 \%$ & $24 \%$ & $43 \%$ & $8 \%$ & $20 \%$ & $21 \%$ & $26 \%$ & $23 \%$ & $18 \%$ \\
\hline 2014 & $8 \%$ & $22 \%$ & $35 \%$ & $7 \%$ & $21 \%$ & $15 \%$ & $17 \%$ & $18 \%$ & $15 \%$ \\
\hline 2013 & $7 \%$ & $13 \%$ & $22 \%$ & $5 \%$ & $10 \%$ & $13 \%$ & $13 \%$ & $12 \%$ & $10 \%$ \\
\hline Before 2013 & $66 \%$ & $0 \%$ & $0 \%$ & $11 \%$ & $23 \%$ & $32 \%$ & $24 \%$ & $22 \%$ & $26 \%$ \\
\hline \multicolumn{10}{|l|}{ Gender } \\
\hline Female & $28 \%$ & $40 \%$ & $0 \%$ & $83 \%$ & $28 \%$ & $36 \%$ & $32 \%$ & $31 \%$ & $32 \%$ \\
\hline \multicolumn{10}{|l|}{ Distance to/from } \\
\hline \multicolumn{10}{|l|}{ Politecnico } \\
\hline$<2.5 \mathrm{~km}$ & $23 \%$ & $22 \%$ & $29 \%$ & $25 \%$ & $6 \%$ & $1 \%$ & $80 \%$ & $\mathbf{3 8} \%$ & $13 \%$ \\
\hline $2.5-4.5 \mathrm{~km}$ & $21 \%$ & $32 \%$ & $35 \%$ & $14 \%$ & $\mathbf{5 5} \%$ & $4 \%$ & $13 \%$ & $30 \%$ & $21 \%$ \\
\hline $4.5-10.5 \mathrm{~km}$ & $23 \%$ & $15 \%$ & $9 \%$ & $19 \%$ & $39 \%$ & $25 \%$ & $7 \%$ & $21 \%$ & $28 \%$ \\
\hline$>10.5 \mathrm{~km}$ & $33 \%$ & $16 \%$ & $2 \%$ & $46 \%$ & $0 \%$ & $71 \%$ & $0 \%$ & $11 \%$ & $37 \%$ \\
\hline \multicolumn{10}{|l|}{ Duration to/from } \\
\hline \multicolumn{10}{|l|}{ Politecnico } \\
\hline$<15 \min$ & $20 \%$ & $26 \%$ & $34 \%$ & $9 \%$ & $4 \%$ & $3 \%$ & $70 \%$ & $36 \%$ & $8 \%$ \\
\hline $15-30 \mathrm{~min}$ & $31 \%$ & $40 \%$ & $43 \%$ & $24 \%$ & $64 \%$ & $8 \%$ & $29 \%$ & $41 \%$ & $28 \%$ \\
\hline $30-45 \mathrm{~min}$ & $16 \%$ & $16 \%$ & $16 \%$ & $19 \%$ & $30 \%$ & $15 \%$ & $1 \%$ & $11 \%$ & $23 \%$ \\
\hline $45-60 \mathrm{~min}$ & $16 \%$ & $13 \%$ & $7 \%$ & $30 \%$ & $1 \%$ & $45 \%$ & $0 \%$ & $8 \%$ & $24 \%$ \\
\hline
\end{tabular}


European Transport $\backslash$ Trasporti Europei (2020) Issue 79, Paper n 1, ISSN 1825-3997

\begin{tabular}{|c|c|c|c|c|c|c|c|c|c|}
\hline $60-75 \min$ & $8 \%$ & $4 \%$ & $0 \%$ & $11 \%$ & $0 \%$ & $16 \%$ & $0 \%$ & $2 \%$ & $9 \%$ \\
\hline $75-90 \mathrm{~min}$ & $6 \%$ & $1 \%$ & $0 \%$ & $6 \%$ & $0 \%$ & $10 \%$ & $0 \%$ & $1 \%$ & $6 \%$ \\
\hline$>90 \min$ & $2 \%$ & $0 \%$ & $0 \%$ & $1 \%$ & $0 \%$ & $3 \%$ & $0 \%$ & $1 \%$ & $2 \%$ \\
\hline \multicolumn{10}{|l|}{ Modes used } \\
\hline $\mathrm{PT}$ & $76 \%$ & $76 \%$ & $71 \%$ & $\mathbf{9 0} \%$ & $92 \%$ & $82 \%$ & $52 \%$ & $66 \%$ & $88 \%$ \\
\hline $\mathrm{IM}$ & $29 \%$ & $16 \%$ & $14 \%$ & $30 \%$ & $11 \%$ & $53 \%$ & $3 \%$ & $15 \%$ & $30 \%$ \\
\hline $\mathrm{BS}$ & $9 \%$ & $10 \%$ & $15 \%$ & $5 \%$ & $15 \%$ & $4 \%$ & $10 \%$ & $10 \%$ & $11 \%$ \\
\hline $\mathrm{AC}$ & $\mathbf{5 9} \%$ & $56 \%$ & $66 \%$ & $42 \%$ & $49 \%$ & $32 \%$ & $96 \%$ & $69 \%$ & $45 \%$ \\
\hline \multicolumn{10}{|l|}{ Journey cost } \\
\hline Unsatisfied & $41 \%$ & $33 \%$ & $27 \%$ & $45 \%$ & $30 \%$ & $55 \%$ & $22 \%$ & $9 \%$ & $67 \%$ \\
\hline \multicolumn{10}{|c|}{ Journey duration } \\
\hline Unsatisfied & $44 \%$ & $38 \%$ & $35 \%$ & $\mathbf{5 8} \%$ & $44 \%$ & $68 \%$ & $11 \%$ & $12 \%$ & $76 \%$ \\
\hline \multicolumn{10}{|c|}{ Parking availability } \\
\hline Unsatisfied & $70 \%$ & $63 \%$ & $66 \%$ & $\mathbf{5 9} \%$ & $66 \%$ & $73 \%$ & $\mathbf{5 9} \%$ & $45 \%$ & $\mathbf{9 0} \%$ \\
\hline \multicolumn{10}{|l|}{ Car sharing } \\
\hline EA & $26 \%$ & $24 \%$ & $43 \%$ & $10 \%$ & $29 \%$ & $10 \%$ & $44 \%$ & $32 \%$ & $22 \%$ \\
\hline IN & $39 \%$ & $42 \%$ & $32 \%$ & $45 \%$ & $40 \%$ & $40 \%$ & $36 \%$ & $38 \%$ & $40 \%$ \\
\hline NI & $25 \%$ & $22 \%$ & $19 \%$ & $24 \%$ & $21 \%$ & $32 \%$ & $15 \%$ & $21 \%$ & $24 \%$ \\
\hline UN & $10 \%$ & $12 \%$ & $6 \%$ & $21 \%$ & $10 \%$ & $18 \%$ & $5 \%$ & $9 \%$ & $14 \%$ \\
\hline
\end{tabular}




\subsection{Results: student cluster.}

When the socioeconomics variables are considered as features for the co-clustering in the student dataset (third column of Table 5), four different clusters of respondents are identified, as in the personnel case. However, these clusters do not reveal four different attitudes towards car sharing (second to fifth column in Table 7), as it happened when considering the personnel dataset. The most well-identified socioeconomic cluster allows the profiling of early adopters students, who have been studying at Politecnico since at least two years and are males living in the Turin municipality (Clus_ST_E_EA). This group has therefore shorter commuting trips and again uses more bike sharing and other active means than the average, being rather satisfied with the cost and time of their trip. The fact that no freshman belongs to this cluster (no elements in the "2016" row) could be related to the restriction for newly-qualified driver in the car sharing registration. On the opposite,Clus_ST_E_UN collects students that are less aware of car sharing than the average. They are mainly freshmen (more precisely, "freshwomen") living in "Prima Cintura", using public transport and personal vehicle to reach university, with a low use of "greener" modes (bike sharing and active modes). The absence of knowledge of the service could be due to their young age and to the fact that car sharing is not available outside Turin. However, considering their relatively higher use of public transport to get in the city centre, this shared mode could be an interesting option for their "last mile" displacement. The remaining two clusters discriminated two different socioeconomic groups of students that however have the same views and behaviours related to car sharing.

The use of travel-related variables in the definition of the cluster again allows the creation of a cluster (Clus_ST_T_EA) that is containing a lot of early adopters (sixth, seventh and eighth column in Table 7). Given the more homogeneous sociodemographic characteristics of university students, the study of their travel habits seems therefore sufficient to identify those that are prone to car sharing use. This cluster is characterised by very short commuting trips that are mainly done through walk and bike: as a consequence, satisfaction levels for their commuting time is very high. Clus_ST_T_NN, instead, seems to collect students either not interested in the service or not even knowing it. The most used modes in this cluster are individual modes and public transport and the least used is, not surprisingly, bike sharing, with a low satisfaction level for cost, duration and parking availability. Despite such dissatisfaction, the use of alternative modes seems not attractive to them so that awareness raising campaigns should particularly be targeted to such cluster.

The co-clustering technique applied to the satisfaction related variables (last column of Table 5) is again identifying an early adopters cluster of students (Clus_ST_S_EA) that is characterised by a relatively higher satisfaction level for their commuting trips. Quite interestingly, the same analysis on the personnel dataset had rather delineated a cluster of people that are interested but did not yet subscribe to a car sharing service (Clus_PE_S_IN). In other words, interested students were quicker in adopting car sharing, while workers show more behavioural inertia that is slowing the transition from a positive attitude towards car sharing to its actual adoption. On the other hand, students not satisfied with their trip (Clus_ST_S_X) are not characterised by a higher than average interest in car sharing, as previously found for the personnel (Clus_PE_S_IN). More in general, it was not possible to derive a cluster of students either interested in car sharing (although not yet using it) or at all not interested in car sharing in any of our analyses. 
Jointly considered, those results show, on one hand that university students could be more easily converted to car sharing because of their higher flexibility in their mobility habits, on the other a large number of potential car sharing users among students actually already subscribed to such service. In this latter case, marketing actions should probably more focused in orienting the use of car sharing services towards the partial or total substitution of the private car, rather than simply adopting such service.

\section{Conclusion and discussion}

In this paper, some analyses on a dataset stemming from a mobility survey administered among both staff and students of the technical university of Turin are proposed. The main aim of the questionnaire was to better understand the mobility habits of the people, both students and personnel, travelling daily to reach the campus, with a specific focus on the interest of the respondents in the subscription to a car sharing service. The objective of this study was to check to which extent different combinations of socioeconomics, travelrelated or travel satisfaction related features are shared among individuals which are either early adopters, interested, not interested or unaware of car sharing services. At the same time, the application of the co-clustering technique helped in providing a set of results in a rather lean way avoiding the application of modelling approaches to explain the data. This aspect can help in the analysis of mobility information collected through surveys in a specific domain, such as a campus, with a mobility management perspective. The results obtained could help in better addressing initiatives and incentives to the proper users with the aim of proposing more sustainable mean of reaching university.

Based on the findings of the above research, the main conclusions and related policy recommendations are as follows:

- When merely looking at descriptive statistics, early adopters of car sharing services are clearly living more in the Turin municipality where this service is available, therefore tend to have shorter commuting trips and use more active means. Car sharing is also more likely to be adopted by people that show more multimodal behaviours, while university personnel that commutes by car tends not to use other means and shows less interest in car sharing.

- Among university workers, a group of younger females living in the outer part of the metropolitan city showed a good interest in car sharing, although they are not using it, probably due to a lack of availability in the place where they live. Since this group tend to have longer commuting trips often made by car, from a mobility management perspective car sharing could be used as a complement to other means such as public transport through intermodal nodes, following a "last mile" mobility approach (Morgavi and Di Loreto, 2017).

- The availability of a parking place near the home and/or the workplace is negatively affecting the interest in car sharing, and it is especially associated with senior staff that is more exclusively commuting by car. In such case, a revision of parking policies inside the campus is probably the most effective way to promote more environmentally sustainable mobility behaviours that would benefit the whole metropolitan area.

- Among those that declare their interest in car sharing, a larger use of active means and a smaller use of the personal car are likely to be correlated to higher chances of really switching to this new mobility service. Conversely, travel-related satisfaction ratings are likely to be predictors of the interest or lack of interest in it. 
- Compared to workers, students are more prone to car sharing adoption, not only for budget reasons or for their interest in new technologies but also for their less consolidated travel habits. This difference confirm the influence that the status has in a car sharing interest, as found in (Zheng et al., 2009). Therefore, it would probably be easier to build a model that is predicting the early adoption of car sharing among students, compared to a model studying the general population on the basis of sociodemographic characteristics or travel patterns. Additionally, since many students interested in car sharing probably already subscribed to this service, car sharing marketing actions should aim at minimising the use of private cars and maximise the complementarity with public transport and active means. On the other hand, students either not interested or unaware of car sharing are less easily identifiable and awareness raising campaigns seems more appropriate to them.

The implementation and development of car sharing within a mobility management perspective must be judiciously conducted in order to avoid unwanted secondary effect, such as substituting trips done by public transport or through active means. In our analyses, a good proportion of early adopters are also consistently using active modes and, in the case of staff, also bike sharing. According to our results, the satisfaction for cost and time of the journey to reach university is very high when biking and walking are used. The main reasons behind their choice are the convenience, the connections with other modes and the possibility to move in the city. Clearly, policy actions targeted to promote car sharing among these groups should not jeopardise such good mobility habits. Related socioeconomic profiles delineate people rather concerned with sustainability and money issues, as could be young students not having their own salary that cannot afford the expenses for a private vehicle. Targeted actions towards such groups of respondents could therefore be the possibility of integrating all smart cards and tickets related to different mobility services in their personal university card. As said previously, this is already possible for both the bike sharing and the public transport pass for students in Turin. This could be done, in the future, for car sharing too.

\section{References}

Anable, J. (2005) "Complacent Car Addicts"; or "Aspiring Environmentalists"? Identifying travel behaviour segments using attitude theory', Transport Policy, 12(1), pp. 65-78. doi: 10.1016/j.tranpol.2004.11.004.

Balsas, C. J. . (2003) 'Sustainable transportation planning on college campuses', Transport Policy, 10(1), pp. 35-49. doi: 10.1016/S0967-070X(02)00028-8.

Bignami, D. F. et al. (eds) (2017) Electric Vehicle Sharing Services for Smarter Cities. doi: 10.1007/978-3-319-61964-4.

Ceccato, R. and Diana, M. (2019) 'Substitution and complementarity patterns between traditional transport means and car sharing: a person and trip level analysis', Transportation, in press. doi: 10.1007/s11116-018-9901-8.

Ciari, F. and Axhausen, K. W. (2012) 'Choosing carpooling or carsharing as a mode: Swiss stated choice experiments', 91st Annual Meeting of Transportation Research Board.

Clewlow, R. R. (2016) 'Carsharing and sustainable travel behavior: Results from the San Francisco Bay Area', Transport Policy, 51, pp. 158-164. doi: 10.1016/j.tranpol.2016.01.013.

Clewlow, R. R. and Mishra, G. S. (2017) 'Shared Mobility: Current Adoption, Use, and 
Potential Impacts on Travel Behavior', in TRB 96th Annual Meeting Compendium of Papers, Washington D.C., pp. 1-18.

Costain, C., Ardron, C. and Habib, K. N. (2012) 'Synopsis of users' behaviour of a carsharing program: A case study in Toronto', Transportation Research Part A: Policy and Practice, 46(3), pp. 421-434. doi: 10.1016/j.tra.2011.11.005.

Danielis, R. et al. (2015) The potential demand for carsharing from university students : an Italian case study, SIET Società Italiana di Economia dei Trasporti e della Logistica, ISSN: 1973-3208.

Dhillon, I. S., Mallela, S. and Modha, D. S. (2003) 'Information-theoretic co-clustering', in Proceedings of the ninth ACM SIGKDD international conference on Knowledge discovery and data mining - KDD '03. New York, New York, USA: ACM Press, p. 89. doi: $10.1145 / 956750.956764$.

Diana, M. (2010) 'From mode choice to modal diversion: A new behavioural paradigm and an application to the study of the demand for innovative transport services', Technological Forecasting and Social Change, 77(3), pp. 429-441. doi: 10.1016/j.techfore.2009.10.005.

Dias, F. F. et al. (2017) 'A behavioral choice model of the use of car-sharing and ridesourcing services', Transportation, 44(6), pp. 1307-1323. doi: 10.1007/s11116-0179797-8.

Erdoğan, S., Cirillo, C. and Tremblay, J. M. (2015) 'Ridesharing as a Green Commute Alternative: A Campus Case Study', International Journal of Sustainable Transportation, 9(5), pp. 377-388. doi: 10.1080/15568318.2013.800619.

Goodman, L. A. and Kruskal, W. H. (1954) 'Measures of association for cross classification', Journal of the American Statistical Association, 49(268), pp. 732764.

Ienco, D. et al. (2013) 'Parameter-less co-clustering for star-structured heterogeneous data', Data Mining and Knowledge Discovery, 26(2), pp. 217-254. doi: 10.1007/s10618-012-0248-z.

Kopp, J., Gerike, R. and Axhausen, K. W. (2015) 'Do sharing people behave differently? An empirical evaluation of the distinctive mobility patterns of free-floating carsharing members', Transportation, 42(3), pp. 449-469. doi: 10.1007/s11116-0159606-1.

Lavery, T. A., Páez, A. and Kanaroglou, P. S. (2013) 'Driving out of choices: An investigation of transport modality in a university sample', Transportation Research Part A: Policy and Practice. Elsevier Ltd, 57, pp. 37-46. doi: 10.1016/j.tra.2013.09.010.

Longo, G., Medeossi, G. and Padoano, E. (2015) 'Multi-criteria analysis to support mobility management at a university campus', Transportation Research Procedia, 5, pp. 175-185. doi: 10.1016/j.trpro.2015.01.019.

Marchionni, G., Ponti, M. and Studer, L. (2017) 'System Sizing Model—Simulation Model of the Service', in Bignami, D. et al. (eds) Electric Vehicle Sharing Services for Smarter Cities. Research for Development. Springer, pp. 265-275.

Moniruzzaman, M. and Farber, S. (2018) 'What drives sustainable student travel? Mode choice determinants in the Greater Toronto Area', International Journal of Sustainable Transportation. Taylor \& Francis, 12(5), pp. 367-379. doi: 10.1080/15568318.2017.1377326.

Morgavi, C. and Di Loreto, G. (2017) Il Car Sharing in Italia. Study by Bain \& Company Italy, Inc. in collaboration with ANIASA. 
de Oña, J., de Oña, R. and López, G. (2016) 'Transit service quality analysis using cluster analysis and decision trees: a step forward to personalized marketing in public transportation', Transportation, 43(5), pp. 725-747. doi: 10.1007/s11116-015-96150.

de Oña, R. et al. (2014) 'Cluster Analysis for Diminishing Heterogeneous Opinions of Service Quality Public Transport Passengers', Procedia - Social and Behavioral Sciences, 162, pp. 459-466. doi: 10.1016/j.sbspro.2014.12.227.

Osservatorio nazionale sulla sharing mobility (2016) $l^{\wedge}$ rapporto nazionale 2016 la Sharing Mobility in Italia: numeri, fatti e potenzialità.

Pirra, M. and Diana, M. (2016) 'Classification of Tours in the U.S. National Household Travel Survey through Clustering Techniques', Journal of Transportation Engineering, 142(6), pp. 1-13. doi: 10.1061/(ASCE)TE.1943-5436.0000845.

Pirra, M. and Pensa, R. G. (2019) 'Comparing Transport Quality Perception among Different Travellers in European Cities through Co-Cluster Analysis', Sustainability, 11, 7159. doi: 10.3390/su11247159.

Rotaris, L. and Danielis, R. (2014) 'The impact of transportation demand management policies on commuting to college facilities: A case study at the University of Trieste, Italy', Transportation Research Part A: Policy and Practice, 67, pp. 127-140. doi: http://dx.doi.org/10.1016/j.tra.2014.06.011.

Rotaris, L. and Danielis, R. (2015) 'Commuting to college: The effectiveness and social efficiency of transportation demand management policies', Transport Policy, 44, pp. 158-168. doi: 10.1016/j.tranpol.2015.08.001.

Schneider J, R. and Hu, L. (2014) 'Bicycle and Bus Commuting to an Urban Campus: Overcoming the Barriers', in TRB 93rd Annual Meeting Compendium of Papers, Washington D.C., pp. 1-23.

Shaheen, S. A. and Cohen, A. P. (2013) 'Carsharing and Personal Vehicle Services: Worldwide Market Developments and Emerging Trends', International Journal of Sustainable Transportation, 7(1), pp. 5-34. doi: 10.1080/15568318.2012.660103.

Shannon, T. et al. (2006) 'Active commuting in a university setting: Assessing commuting habits and potential for modal change', Transport Policy, 13(3), pp. 240253. doi: 10.1016/j.tranpol.2005.11.002.

Sheeran, P. (2002) 'Intention-Behavior Relations: A Conceptual and Empirical Review', European Review of Social Psychology, 86(12 (1)), pp. 1-36. doi: 10.1080/14792772143000003.

Tan, P.-N., Steinbach, M. and Kumar, V. (2005) Introduction to data mining. Pearson Addison Wesley.

Urbi (2017) Car Sharing Facts - "Smart Mobility in Smart Cities" convention, 14 March 2017, Milan, Italy.

Zheng, J. et al. (2009) 'Carsharing in a University Community', Transportation Research Record: Journal of the Transportation Research Board, 2110, pp. 18-26. doi: 10.3141/2110-03.

Zhou, J. (2014) 'Carsharing on university campus: Subsidies, commuter benefits, and their impacts on carsharing', Transportation Research Part D: Transport and Environment, 32, pp. 316-319. doi: 10.1016/j.trd.2014.08.015.

Zhou, J. (2016) 'Proactive sustainable university transportation: Marginal effects, intrinsic values, and university students' mode choice', International Journal of Sustainable Transportation. Taylor \& Francis, 10(9), pp. 815-824. doi: 10.1080/15568318.2016.1159357. 
European Transport $\backslash$ Trasporti Europei (2020) Issue 79, Paper n 1, ISSN 1825-3997

\section{Acknowledgements}

Data collection activities presented in this article were part of a collaboration between Politecnico di Torino and General Motors Powertrain - Europe with the scope of investigating the general interest in a car sharing system among the people working and studying at the campus. 